\title{
KESADARAN MEREK MENINGKAT KARENA PERIKLANAN DAN HUBUNGAN MASYARAKAT (Studi Pada Konsumen Maskapai Penerbangan Citilink)
}

\author{
Agung Rachmadi S \\ Department of Management FEB UMM \\ E-mail : rahmadii.agung@gmail.com
}

\begin{abstract}
In this study, researcher aims to discuss about advertising and public relations as tools to create brand awareness on Citilink Airlines. This study was a quantitative research appertaining descriptive research. Sampling technique in this study was nonprobability sampling with purposive sampling method with 100 respondents who stay in Malang Raya and respondents must be more than 17 years old and stay in Malang for long periode of time or just for awhile and know Citilink Airlines. Analyze tool of data which used was multiple regression analyze. The results of this study is advertising and public relations have significant effect on brand awareness as parsial
\end{abstract}

Key words: Advertising, Public Relations, Brand Awareness

\section{PENDAHULUAN}

Industri penerbangan Indonesia adalah industri yang berkembang, semakin cerdas, sadar harga, dan memiliki persaingan yang kompetitif. Persaingan yang kompetitif ini dialami tidak hanya dengan maskapai penerbangan domestik tetapi juga dengan maskapai penerbangan internasional. Persaingan dengan maskapai penerbangan domestik yang semakin marak tentu saja berdampak pada pencapaian operasional perusahaan. Apalagi saat ini semakin banyak maskapai penerbangan Indonesia berbiaya rendah yang menawarkan tiket dengan harga murah dengan tujuan untuk merebut pangsa pasar

yang lebih banyak di masyarakat salah satunya Citilink.

Citilink merupakan salah satu maskapai dengan penerbangan berbiaya rendah yang ada di Indonesia. Maskpai yang berdiri pada tahun 2001 ini ingin menguasai pasar LCC (low cost carrier) di Indonesia. Pesaing terberat dari Citilink ialah Airasia dan Lion Air yang telah menguasi pasar Indonesia dan juga brand image yang kuat dari kedua maskpai tersebut. Dari data yang didapat Citilink menempati posisi ke 
3 dalam penggunaan jasa penerbangan LCC.

Tabel 1. Jumlah Penumpang LCC di Indonesia tahun 2010-2014

\begin{tabular}{|c|l|l|l|l|l|l|}
\hline $\begin{array}{l}\mathbf{N} \\
\mathbf{0}\end{array}$ & Airline & $\begin{array}{l}\mathbf{2 0 1 0} \\
\mathbf{p a x}\end{array}$ & $\mathbf{2 0 1 1}$ & $\mathbf{2 0 1 2}$ & $\mathbf{2 0 1 3}$ & $\mathbf{2 0 1 4}$ \\
\hline 1 & Lion Air & 20.5 & 25.9 & 30.2 & 34.1 & $36^{*}$ \\
\hline 2 & $\begin{array}{l}\text { Indonesi } \\
\text { a } \\
\text { AirAsia }\end{array}$ & 3.9 & 5.0 & 5.8 & 7.9 & 7.9 \\
\hline 3 & Citilink & 1.1 & 1.6 & 2.9 & 5.3 & 7.6 \\
\hline 4 & $\begin{array}{l}\text { Wings } \\
\text { Air }\end{array}$ & 0.8 & 2.1 & 2.7 & 3.6 & $4^{*}$ \\
\hline 5 & $\begin{array}{l}\text { Mandala } \\
*\end{array}$ & 3.5 & 0 & 0.3 & 1.9 & 0.7 \\
\hline $\begin{array}{l}\text { Lion+W } \\
\text { ings } \\
\text { (LionGro } \\
\text { up) }\end{array}$ & 21.4 & 28.1 & 32.9 & 37.7 & $40^{*}$ \\
\hline TOTAL & $\mathbf{2 9 . 9}$ & $\mathbf{3 4 . 7}$ & $\mathbf{4 1 . 9}$ & $\mathbf{5 2 . 8}$ & $\mathbf{5 6}^{*}$ \\
\hline
\end{tabular}

Catatan: * Mandala berhenti beroperasi pada awal 2011 dan beroprasi kembali pada pertengahan 2012 dengan nama Tigerair dan kembali diberhentikan pada juli 2014 Sumber: CAPA - Center for Aviation

Merek Citilink belum dapat melekat di pikiran masyarakat dan menjadi top of mind brand. Hasil survey yang dilakukan oleh Top Brand Award dalam kategori maskapai menempatkan Citilink dalam posisi 4 , yang artinya merek tersebut tidak termasuk dalam top brand.

Tabel 2. Top Brand Index 2015 Fase

1 Maskapai

\begin{tabular}{|c|l|c|c|}
\hline NO & \multicolumn{1}{|c|}{ Merek } & TBI & TOP \\
\hline 1 & $\begin{array}{l}\text { Garuda } \\
\text { Indonesia }\end{array}$ & $40.0 \%$ & TOP \\
\hline 2 & Lion Air & $35.1 \%$ & TOP \\
\hline 3 & Air Asia & $8.7 \%$ & \\
\hline 4 & Citilink & $4.4 \%$ & \\
\hline 5 & $\begin{array}{l}\text { Sriwijaya } \\
\text { Air }\end{array}$ & $4.4 \%$ & \\
\hline
\end{tabular}

Citilink berusaha untuk menaikan kesadaran akan merek mereka di masyarakat dengan berbagai kegiatan promosi. Kesadaran merek menurut Aaker dalam Rangkuti (2009:39) adalah kesanggupan seseorang calon pembeli untuk mengenali atau mengingat kembali bahwa suatu merek merupakan bagian dari kategori produk tertentu. Kesadaran merek yang kuat disuatu produk akan meningkatkan penjualan pada produk tersebut pula. Tidak ada suatu perusahaan yang tidak ingin mereknya sukses di pasaran dan menjadi top of mind.

Agar merek menjadi top of mind di pasar perusahaan perlu melakukan promosi Promosi adalah salah satu dari empat unsur utama dari bauran pemasaran (marketing mix). Periklanan, hubungan masayarakat dan publisitas, promosi penjualan, penjualan secara personalia, dan penjualan secara langsung merupakan bauran dari promosi.

Perusahaan memakai berbagai macam bauran promosi tergantung dari maksud dan tujuan perusahaan. Periklanan bertujuan untuk menginformasikan suatu produk seperti cara kerja atau kegunaan produk yang diiklankan. Periklanan juga mengingatkan kembali akan merek/produk dari perusahan dan juga membangun kesadaran merek dan juga yang pasti merangsang terjadinya penjualan.

Promosi penjualan ini bertujuan untuk mendongkrak penjualan pada pada waktu yang singkat. Contoh kegitannya berupa pemberian diskon, hadiah, pemberian garansi dan lain sebagainya. Beda dengan sales promotion, penjualan secara personal tujuan untuk mempengaruhi konsumen untuk membeli produk atau jasa yang ditawarkan melalui 
interaksi langsung orang per orang. Sama halnya dengan penjualan secara personal, penjualan secara langsung tujuan agar konsumen membeli barang atau jasa mereka melalui media seperti direct mail, katalok, peragaan produk-produk dan lain sebagainya yang diberikan kepada konsumen secara lansgung.

Peneliti memilih periklanan yang mana keterkaitan kesadaran merek lebih tepat dari pada alat-alat promosi lainnya karena salah satu tujuan periklanan membangun kesadarn merek konsumen yang mana ini merupakan permasalah dari Citilink yang mana kesadaran masyarakat akan merek Citilink masih rendah. Humas yang sebenernya lebih berfokus kepada penguatan image namun beberapa kegiatannya juga dapat menguatakan kesadaran merek.

Berdasarkan uruain diatas, penulis memiliki ketertarikan untuk meneliti lebih lanjut dengan mengadakan penelitian yang berjudul "Kesadaran Merek Meningkat Karena Periklanan Dan Hubungan Masyarakat (Studi Pada Maskapai Penerbangan Citilink)."

\section{TINJUAN PUSTAKA}

Perilaku konsumen menurut Lamb, Hair dan McDaniel (2001:188) merupakan suatu proses seorang pelanggan dalam membuat keputusan membeli, juga untuk menggunakan dan membuang barang-barang dan jasa yang dibeli, juga termasuk faktor-faktor yang mempengaruhi keputusan pembelian dan penggunaan produk. Dengan mengetahui perilaku yang ditunjukkan oleh konsumen maka akan membantu produsen untuk menciptakan suatu produk yang sesuai dengan yang diinginkan oleh konsumen.

Dimensi-dimensi tersebut digabungkan dalam satu model mengenai bagaimana konsumen mengambil keputusan yang disebut model perilaku konsumen.

Sumber : Kotler dan Keller (2008)

Kesadaran Merek, Menurut Shimp (2003:11), Kesadaran merek merupakan kemampuan sebuah merek untuk muncul dalam benak konsumen ketika mereka sedang memikirkan kategori produk tertentu dan seberapa mudahnya nama tersebut dimunculkan. Kesadaran merek memiliki tingkatan-tingkat yang dapat digambarkan dalam suatu piramida di bawah ini. Durianto dkk. (2001:55,58-59)

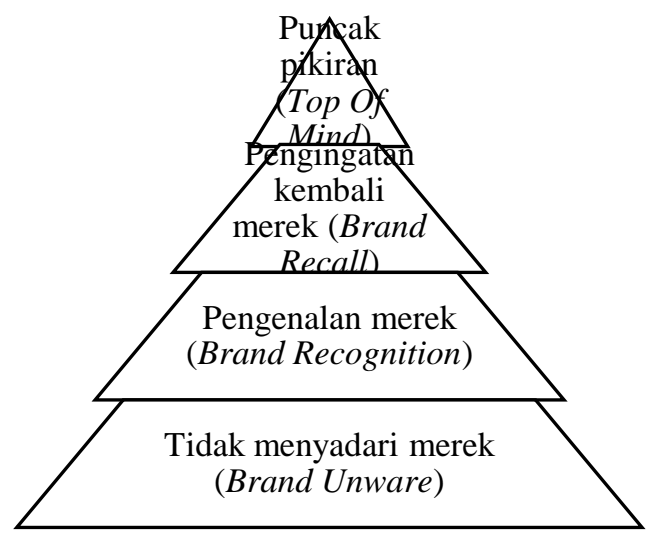

Gambar 1. Piramida

Periklanan menurut Kotler dan Armstrong (2008:150), adalah semua bentuk terbayar dari presentasi nonpribadi dan promosi ide,barang, atau jasa oleh sponsor tertentu. Fungsi dari periklanan menurut Shimp (2003:357) ialah menginformasi agar konsumen sadar akan merek-merek baru, mendidik mereka tentang berbagai fitur dan manfaat merek, serta memfasilitasi penciptaan merek 
yang positif, membujuk pelanggan untuk mencoba produk dan jasa yang di iklankan, mengingatkan agar merek perusahaan tetap segar dalam ingatan para konsumen, dan sebagai nilai tambah pada merek dengan mempengaruhi persepsi konsumen.

Hubungan masyarakat adalah Interaksi dan menciptakan opini publik sebagai input yang menguntungkan untuk kedua belah pihak, dan merupakan profesi yang profesional dalam bidangnya karena merupakan faktor yang sangat penting dalam pencapaian tujuan organisasi dengan secara tepat dan dengan secara terus menerus karena hubungan masyarakat merupakan kelangsungan hidup organisasi yang bersangkutan (Maria, 2002, p.7).

Menurut Suhandang (2004), tugas hubungan masyarakat adalah sinkronisasi antara informasi dari perusahaan dengan reaksi dan tanggapan publik sehingga mencapai suasana akrab, saling mengerti, serta muncul suasana yang menyenangkan dalam interaksi perusahaan dengan publik. Dengan demikian peran humas tersebut bersifat dua arah yaitu berorientasi kedalam (inward looking) dan keluar (outward looking).

Marketing public relations merupakan perpaduan antara pelaksanaan program dan strategi pemasaran dengan aktivitas program kerja hubungan masyarakat dalam upaya meluaskan pemasaran dan demi mencapai kepuasan konsumen. Hubungan masyarakat dapat memperluas peranannya dalam bidang pemasaran, dan banyak pengelolah pemasaran menerapkan hubungan masyarakat sebagai pendukung unsur promosi dalam bauran pemasaran, humas digunakan dalam perencanaan pemasaran untuk mencapai sejumlah sasaran, sebagai berikut : Membantu perusahaan dan nama produknya agar lebih dikenal, Membantu mengenalkan produk baru atau peningkatan produk, Membantu meningkatkan suatu produk, seperti dalam menyempurnakan pesan iklan dan promosi dengan menambah informasi baru, Mencari pangsa pasar baru dan memperluas keberadaannya, dan Memantapkan semua citra yang positif bagi produk dan usahanya. (Ardianto , 2009:121)

Berdasarkan tinjauan pustaka yang telah dikemukakan, maka kerangka pemikiran dalam penelitian ini dapat dilihat pada gambar sebagai berikut:

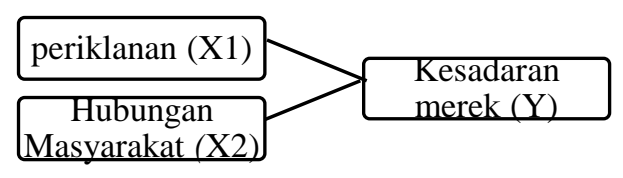

Gambar 2. Kerangka Konseptual Hipotesis dalam penelitian ini adalah sebagai berikut :

H1 : Semakin menarik periklanan yang dilakukan oleh Citilink maka semakin besar pula kesadaran merek yang terbentuk di benak konsumen.

$\mathrm{H} 2$ : Semakin intens kegiiatan hubungan masyarakat yang dilakukan oleh Citilink maka semakin besar pula kesadaran merek yang terbentuk di benak konsumen.

\section{METODE PENELITIAN}

Penelitian ini dilakukan di Malang Raya. Jenis penelitian yang digunakan dalam penelitian ini adalah penelitian deskriptif dengan 
pendekatan kuantitatif.

Populasi dalam penelitian ini adalah masyarakat yang tinggal di Malang Raya yang berusia 17 tahun ke atas, baik itu masyarakat asli atau pendatang yang mengetahui maskapai Citilink.

Jumlah sampel sebanyak 100 responden yang mengetahui maskapai penerbangan Citilink berusia 17 tahun ke atas, memiliki KTP Malang Raya (kota Malang, kab. Malang, dan kota Batu), dan masyarakat pendatang yang berdomisili di Malang Raya dengan masa waktu tinggal lebih dari 1 bulan. Metode pengambilan sampel yang digunakan dalam penelitian ini adalah purposive sampling yang dapat dikatakan sebagai secara sengaja mengambil sampel tertentu sesuai persyaratan (sifat-sifat, karakteristik, ciri, kriteria) sampel.

Teknik pengumpulan data yang dilakukan dengan mengajukan lembaran angket yang berisi daftar pertanyaan kepada responden. Interval pertanyaan dalam angket ini adalah 1-5 dengan pernyataan jangkarnya Sangat Tidak Setuju (STS) hingga Sangat Setuju (SS).

Teknik pengukuran data dalam penelitian ini menggunakan Skala Likert yaitu digunakan untuk mengukur sikap, pendapat, dan persepsi seseorang atau sekelompok orang tentang fenomena sosial yang terjadi. Pengukuran data dalam skala likert. Dalam skala ini menggunakan sangat setuju diberikan nilai 5, setuju diberikan nilai 4 , netral diberikan nilai 3 , tidak setuju diberikan nilai 2 dan sangat tidak setuju diberikan nilai 1.

Definisi operasional variabel yang digunakan dalam penelitian ini sebagai berikut: Periklanan, kemenarikan pesan iklan yang mana iklan tersebut dapat menarik perhatian serta membujuk dan mengajak orang untuk melihat iklan tersebut. Indikator meliputi Iklan menarik perhatian, Iklan menarik minat, Iklan mudah diingat, Frekuensi konsumen melihat iklan (Fatmayanti, 2012).

Hubungan masyarakat, intensitas kegiatan humas yang mengkomunikasikan kepentingan Citilink sehingga menciptakan kesadaran positif. Indikator meliputi Keragaman informasi, Mensponsori kegiatan, Menginformasikan hal-hal baru dari Citilink dan Kedalaman pemberitaan di media masa (Fatchun, 2010).

Kesadaran Merek, kemampuan merek Citilink muncul dalam benak atau pikiran konsumen. Indikator meliputi Merek mudah diingat, Merek menjadi pilihan utama, Diferensiasi merek dan Merek mudah dikenali (Fatmayanti, 2012).

\section{HASIL PENELITIAN DAN PEMBAHASAN}

Berdasarkan hasil uji validitas menunjukkan bahwa seluruh item pernyataan dalam kuesioner dengan derajat bebas $\mathrm{df}=100-2$ mempunyai ( $\mathrm{r}$ hitung) $\geq 0,197$ maka seluruh pernyataan dari variabel periklanan, hubungan masyarakat dan kesadaran merek dinyatakan valid.

Pengujian reliabilitas diketahui bahwa semua variabel tersebut memiliki nilai koefisien Alpha Cronbach lebih besar dari 0,6 sehingga dapat dikatakan instrumen pertanyaan yang digunakan dalam penelitian ini sudah reliabel atau dapat dihandalkan. Jadi pengukuran ini jika digunakan berulang-ulang 
terhadap subjek dan kondisi yang sama maka akan menghasilakn hasil yang relatif konsisten.

Persamaan regresi digunakan mengetahui bentuk hubungan antara variabel bebas dengan variabel terikat yaitu periklanan $\left(\mathrm{X}_{1}\right)$, hubungan masyarakat $\left(\mathrm{X}_{2}\right)$ terhadap variabel terikat yaitu kesadaran merek (Y). Dengan menggunakan bantuan SPSS for Windows ver 21.00 didapat model regresi seperti pada Tabel 1.5:

Tabel 3. Persamaan Regresi

\begin{tabular}{|c|c|c|c|c|c|}
\hline \multirow[t]{2}{*}{ Model } & \multicolumn{2}{|c|}{$\begin{array}{c}\text { UnCoefficient } \\
\mathrm{s}\end{array}$} & std & $\mathrm{T}$ & Sig \\
\hline & B & $\begin{array}{l}\text { Std.Er } \\
\text { ror }\end{array}$ & $\begin{array}{l}\text { Be } \\
\text { ta }\end{array}$ & & \\
\hline $\begin{array}{c}1 \\
\text { (constant) }\end{array}$ & $\begin{array}{l}6,1 \\
95\end{array}$ & 1,220 & & 5,076 & $\mathbf{0 , 0}$ \\
\hline $\begin{array}{l}\text { Periklanan } \\
\left(\mathrm{X}_{1}\right)\end{array}$ & $\begin{array}{l}0,4 \\
35\end{array}$ & 0,087 & $\begin{array}{l}0,4 \\
48\end{array}$ & 4,985 & $\mathbf{0 , 0}$ \\
\hline $\begin{array}{l}\text { Hubungan } \\
\text { Masyaraka } \\
\text { t }(X)\end{array}$ & $\begin{array}{l}0,2 \\
09\end{array}$ & 0,076 & $\begin{array}{l}0,2 \\
47\end{array}$ & 2,747 & $\mathbf{0 , 0}$ \\
\hline
\end{tabular}

Karena penilaian disini tidak ada nol mutlak karena skala pengukuran data menggunakan skala likert dan juga nilai beta tidak dapat diinterpretasikan karena variabel terikat yang diteliti tidak bisa dinterpretasikan dengan angka, maka digunakan persamaan regresi menggunakan standardized coefficients:

$$
Y=\beta_{1} X_{1}+\beta_{2} X_{2}
$$

Berdasarkan pada Tabel 4.11

didapatkan persamaan regresi

sebagai berikut :

$$
\mathrm{Y}=0,448 \mathrm{X}_{1}+0,247 \mathrm{X}_{2}
$$

Dari persamaan di atas dapat diinterpretasikan sebagai berikut:

Kesadaran merek akan meningkat untuk setiap periklanan yang menarik yang dilakukan Citilink. Jadi, apabila periklanan menarik, maka kesadaran merek akan meningkat atau terbentuk, ini dikarenakan hasil beta dalam kofesien standar bernilai positif. Semakin menarik periklanan yang dilakukan oleh Citilink maka semakin besar pula kesadaran merek yang terbentuk dibenak konsumen.

Kesadaran merek akan meningkat untuk setiap intensitas kegiatan hubungan masyarakat. Jadi, apabila intensitas kegiatan hubungan masyarakat ditingkatkan, maka kesadaran merek akan meningkat atau terbentuk, ini dikarenakan hasil beta dalam koefisien standar bernilai positif. Semakain intensitas kegiatan humas yang dilakukan Citilink maka semakin besar pula kesadaran merek yang terbentuk dibenak konsumen.

Tabel 4. Koefisien Korelasi dan Determinasi

\begin{tabular}{cccc}
\hline Model & R & R Square & $\begin{array}{c}\text { Adjusted R } \\
\text { Square }\end{array}$ \\
\hline 1 & $\mathbf{0 , 5 9 6}$ & $\mathbf{0 , 3 5 5}$ & $\mathbf{0 , 3 4 2}$
\end{tabular}

Dari analisis pada Tabel 4 diperoleh hasil koefisien determinasi (adjusted $\mathrm{R}^{2)}$ sebesar 0,342. Artinya bahwa $34,2 \%$ variabel kesadaran merek akan dipengaruhi oleh variabel bebasnya, yaitu periklanan $\left(\mathrm{X}_{1}\right)$ dan hubungan masyarakat $\left(\mathrm{X}_{2}\right)$. Sedangkan sisanya $65,8 \%$ variabel kesadaran merek akan dipengaruhi oleh variabel-variabel yang lain yang tidak dibahas dalam penelitian ini.

Uji $F$ dilakukan untuk mengetahui pengaruh secara bersama - sama atau simultan antara variabel bebas yaitu kualitas periklanan $\left(\mathrm{X}_{1}\right)$ dan hubungan masyarakat $\left(\mathrm{X}_{2}\right)$ terhadap variabel terikat yaitu kesadaran merek (Y).

Berdasarkan penilitian nilai $\mathrm{F}$ hitung sebesar 26,711. Sedangkan F tabel $(\alpha=0.05 ; \mathrm{db}$ regresi $=2: \mathrm{db}$ residual $=97)$ adalah sebesar 3,090. Karena F hitung > F tabel yaitu $26,711>3,090$ atau nilai Sig. $F$ $(0,000)<\alpha=0.05$ maka model analisis regresi adalah signifikan. Hal ini dapat disimpulkan bahwa variabel 
terikat (kesadaran merek) dapat dipengaruhi secara bersama-sama oleh variabel bebas (periklanan $\left(\mathrm{X}_{1}\right)$ dan hubungan masyarakat $\left(\mathrm{X}_{2}\right)$ ).

Uji $t$ digunakan untuk mengetahui apakah masing-masing variabel bebas secara parsial mempunyai pengaruh yang signifikan terhadap variabel terikat. Uji $\mathrm{t}$ atau $\mathrm{t}$ test antara $\mathrm{X}_{1}$ (periklanan) dengan $\mathrm{Y}$ (kesadaran merek) menunjukkan $\mathrm{t}$ hitung $=4,985$. Sedangkan $t$ tabel $(\alpha$ $=0.05 ; \mathrm{db}$ residual $=97)$ adalah sebesar 1,984. Karena $\mathrm{t}$ hitung $>\mathrm{t}$ tabel yaitu 4,985 $>1,984$ atau sig. $\mathrm{t}$ $(0,000)<\alpha=0.05$ maka pengaruh $\mathrm{X}_{1}$ (periklanan) terhadap kesadaran merek adalah signifikan. Hal ini berarti $\mathrm{H}_{0}$ ditolak.

Uji $t$ atau $t$ test antara $X_{2}$ (hubungan masyarakat) dengan $\mathrm{Y}$ (kesadaran merek) menunjukkan $\mathrm{t}$ hitung $=2,747$. Sedangkan $t$ tabel $(\alpha$ $=0.05 ; \mathrm{db}$ residual $=97)$ adalah sebesar 1,984. Karena $t$ hitung $>t$ tabel yaitu 2,747>1,984 atau sig. $\mathrm{t}$ $(0,007)<\alpha=0.05$ maka pengaruh $\mathrm{X}_{2}$ (hubungan masyarakat) terhadap kesadaran merek adalah signifikan pada alpha $5 \%$. Hal ini berarti $\mathrm{H}_{0}$ ditolak.

Berdasarkan hasil analisis data yang telah diketahui sebelumnya diketahui bahwa variabel periklanan memiliki pengaruh yang signifikan terhadap kesadaran merek. Indikator periklanan berupa iklan menarik perhatian, iklan menarik minat, iklan mudah diingat, dan frekuensi cukup sering terlihat secara signifikan dapat mempengaruhi kesadaran merek Citilink. Hasil persamaan regresi yang didapat menghasilkan nilai positif dengan begitu iklan yang menarik akan meningkatkan kesadaran merek. Sehingga semakin menarik iklan yang dilakukan Citilink maka semakin besar pula kesadaran merek yang terbentuk dibenak konsumen. Penelitian ini sejalan dengan penelitian yang dilakukan oleh Clark dkk. (2009) dan Kurniyawait (2014) bahwa periklanan berpengaruh signifikan terhadap kesadaran merek.

Berdasarkan hasil analisis data yang telah diketahui sebelumnya bahwa variabel hubungan masyarakat memiliki pengaruh yang signifikan terhadap kesadaran merek. Kegiatan humas yang dilakukan Citilink dengan indikator keragaman informasi, keikutsertaan sponsorship acara, menginformasikan hal-hal baru dan kedalaman pemberitaan dapat berpengaruh pada kesadaran merek yang ada dibenak masyarakat.

Hal tersebut dibuktikan dari hasil analisis regresi bahwa variabel hubungan masyarakat positif terhadap kesadaran merek, sehingga kegiatan humas diperbanyak maka akan menumbuhkan kesadaran merek pada masyarakat. Hasil uji t juga yang dilakukan juga mengahasilkan bahwa hubungan masyarakat berpengaruh signifikan terhadap kesadaran merek. Jadi semakin intensitas hubungan masyarakat yang dilakukan Citilink maka semakin besar pula kesadaran merek yang terbentuk dibenak konsumen.

Penelitian ini didukung oleh Shafi dan Madhaviah (2013) dan juga penelitian dari Fatchun (2010) dan Dwilestari (2015) yang menyatakan terdapat pengaruh yang signifikan antara hubungan masyarakat. 


\section{SIMPULAN}

Variabel periklanan berpengaruh signifikan terhadap kesadaran merek dengan indikator iklan menarik perhatian, iklan menarik minat, iklan mudah diingat, dan iklan cukup sering terlihat berdampak pada terbentuknya kesadaran merek di benak masyarakat.

Variabel hubungan masyarakat berpengaruh signifikan terhadap kesadaran merek indikator keragaman informasi, keikutsertaan sponsorship, menginformasikan hal-hal baru, dan kedalaman pemberitaan berdampak pada terbentuknya kesadaran merek Citilink di benak masyarakat.

\section{DAFTAR PUSTAKA}

Ardianto, Elvinaro. 2009. Public Relations Pendekatan Praktis Menjadi Komunikator, Orator, Presenter dan Juru Kampanye Handal. Bandung. Widya Padjajaran

CAPA Center For Aviation. 2015. Garuda Indonesia LCC subsidiary Citilink will focus on domestic expansion \& profitability in 2015. http://centreforaviation.com/anal ysis/garuda-indonesia-lccsubsidiary-citilink-will-focuson-domestic-expansion-profitability-in-2015-211114 (diakses tanggal 25/11/2015)

Charles W. Lamb, Joseph F. Hair, Carl Mcdaniel. 2001. Pemasaran. Edisi Pertama, Salemba Empat, Jakarta.

Clark, C. Robert. Doraszelski, Ulrich. Draganska Michaela. 2009. The effect of advertising on brand awareness and perceived quality: $A n$ empirical investigation using panel data. Quant Mark Econ (2009) 7:207-236

Durianto, Darmadi, Sugiarto dan Sitinjak, Tony, 2001. Strategi Menaklukan Pasar Melalui Riset Ekuitas dan Perilaku Merek, Gramedia Pustaka, Jakarta.

Dwilestari, Andika Puspa. 2015. Pengaruh Pelaksanaan Public Relations Melalui Media Sosial Terhadap Brand Awareness. Universitas Katolik Indonesia Atma Jaya. Fatchun, Hasyim. 2010. Pengaruh Kegiatan Promosi Terhadap Kesadaran Merek Dan Implikasinya Pada Perilaku Pembelian Konsumen Politeknik Negeri Semarang. Universitas Diponogoro. Semarang.

Fatmayanti, Susy Raih Nur. 2012. Analisis Iklan dan Endorser Terhadap Pembentukan Brand Awareness Serta Dampaknya Pada Keputusan Pembelian Produk Kecap Manis ABC. Universitas Diponegoro.

Kotler, Philip dan Armstrong Gary, 2008. Prinsip-Prinsip Pemasaran Jilid 1 Edisi 12, Erlangga, Jakarta.

Kotler, Philip \& Keller, Kevin Lane 2008. Manajemen Pemasaran. Edisi 12. Jakarta. PT Indeks.

Kurnyawati, Melynda Dyah dkk. 2014. Pengaruh Iklan Terhadap Brand Awareness Dan Dampaknya Terhadap Keputusan Pembelian (Studi pada Mahasiswa Fakultas Ilmu Administrasi (FIA) Jurusan Administrasi Bisnis 
Universitas Brawijaya Angkatan 2012-2013 yang Menggunakan Produk Sabun Mandi Merek Lifebuoy). Jurnal Administrasi Bisnis (JAB). Vol. 16 No.1.

Shafi, Syed Irfan. Madhavaiah. 2013.

An Empirical Study On Impact Of Promotional Mix Elements On Brand Equity: A Study Offmcg In India. Madras University Journal Of Business And Finance Refereed, Peer-reviewed and Bi-annual Journal from the Department of Commerce. Vol. 1 No. 2 July 2013 Pp. 46 $-56$
Shimp, A. Terence, 2003. Periklanan Promosi Aspek Tambahan Komunikasi Pemasaran Terpadu, Erlangga, Jakarta.

Sr Maria Assumpta. R, 2002, Dasardasar Public Relation, Jakarta : Penerbit Grasindo

Suhandang, Kustadi. 2004. Public Relation Perusahaan. Nuansa. Bandung.

Top Brand Award. 2015. http://www.topbrandaward.com/

Widayat, 2004, Metode Penelitian

Pemasaran, Edisi Pertama, Cetakan

Pertama, Penerbit, CV. Cahaya

Press, Malang 